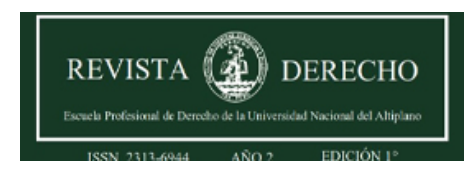

Revista de Derecho

ISSN: 2313-6944

ISSN: 2707-9651

revistaderecho@unap.edu.pe

Universidad Nacional del Altiplano

Perú

\title{
AUSENCIA DE FUNDAMENTO EN LA DETERMINACIÓN DE LA REPARACIÓN CIVIL EN DELITOS DE PELIGRO ABSTRACTO, Y SU AFECTACIÓN AL DERECHO A LA DEBIDA MOTIVACIÓN
}

Calsin Coila, Humberto Juan

AUSENCIA DE FUNDAMENTO EN LA DETERMINACIÓN DE LA REPARACIÓN CIVIL EN DELITOS DE PELIGRO ABSTRACTO, Y SU AFECTACIÓN AL DERECHO A LA DEBIDA MOTIVACIÓN

Revista de Derecho, vol. 7, núm. 1, 2022

Universidad Nacional del Altiplano, Perú

Disponible en: https://www.redalyc.org/articulo.oa?id=671870939001

DOl: https://doi.org/10.47712/rd.2022.v7i1.160

\section{(c) (1)}

Esta obra está bajo una Licencia Creative Commons Atribución 4.0 Internacional. 


\section{AUSENCIA DE FUNDAMENTO EN LA DETERMINACIÓN DE LA REPARACIÓN CIVIL EN DELITOS DE PELIGRO ABSTRACTO, Y SU AFECTACIÓN AL DERECHO A LA DEBIDA MOTIVACIÓN}

\section{ABSENCE OF FOUNDATION IN THE DETERMINATION OF CIVIL REPARATION IN CRIMES OF ABSTRACT DANGER, AND YOUR IMPACT ON THE RIGHT DUE MOTIVATION}

Humberto Juan Calsin Coila

Universidad Nacional del Altiplano, Perú

jhuan_111@hotmail.com
DOI: https://doi.org/10.47712/rd.2022.v7i1.160

Redalyc: https://www.redalyc.org/articulo.oa?

$\mathrm{id}=671870939001$

Recepción: 30 Septiembre 2021

Aprobación: 09 Octubre 2021

Publicación: 03 Enero 2022

\section{RESUMEN:}

La investigación tiene como objetivo general analizar la ausencia de fundamento en la determinación de la reparación civil en delitos de peligro abstracto afecta el derecho a la debida motivación. Se sabe que en los delitos de peligro abstracto no existe daño alguno y por regla general la reparación civil debe imponerse cuando exista daño. Para estudiar el tema se usó el tipo de investigación jurídico-doctrinal, donde se analizó la naturaleza jurídica de la reparación civil, igualmente se analizó los criterios judiciales que tomaron los jueces para determinarse la reparación civil en los delitos de peligro abstracto, así como se analizó si se afectó o no el derecho a la debida motivación al fundamentarse las sentencias condenatorias. Llegándose a las conclusiones siguientes: a) la naturaleza jurídica de la reparación civil es de tendencia privada, b) no existe un criterio de cómo debe determinarse la reparación civil en los delitos de peligro abstracto, menos lo desarrolla el Acuerdo Plenario $\mathrm{N}^{\circ} 06-2006 / \mathrm{CJ}-116$, y, c) los jueces penales de juzgamiento de la provincia de Puno y San Román al fundamentar las sentencias condenatorias en los casos de delitos de peligro abstracto realizaron una motivación aparente respecto de la reparación civil, vulnerando el derecho a la debida motivación de las resoluciones judiciales.

Palabras ClaVE: Daño, delito, derecho fundamental, jurisprudencia, motivación, peligro abstracto y reparación civil.

\section{Abstract:}

The general objective the research is to analyze the absence of a foundation in the determination of civil reparation in crimes of abstract danger affects the right to due motivation. It is known that in crimes of abstract danger there is no damage whatsoever and as a general rule civil reparation must be imposed when there is damage. The type of legal-doctrinal investigation was used, where the legal nature of civil reparation was analyzed, the judicial criteria that judges took to determine civil reparation in crimes of abstract danger were also analyzed, as well as analyzed whether or not the right to due motivation was affected when the convictions were based. Following conclusions: $a$ ) the legal nature of civil compensation is private, $b$ ) there is no criterion on how civil compensation should be determined in crimes of abstract danger, unless it is developed by Plenary Agreement No. 06- 2006/ CJ-116, and, c) the criminal trial judges of the province of Puno and San Román, when founding the convictions in the cases of crimes of abstract danger, made an apparent motivation regarding civil reparation, violating the right to the due motivation of the judicial decisions.

KEYWORDS: Damage, crime, fundamental right, jurisprudence, motivation, abstract danger and civil reparation.

\section{INTRODUCCIÓN}

El Código Penal peruano señala que la sanción punitiva conlleva también la imposición de la sanción pecuniaria, esto es la imposición al imputado de un monto dinerario por concepto de reparación civil

NotAS DE AUTOR

jhuan_111@hotmail.com 
en relación a los daños ocasionados por su conducta delictiva. Peña Cabrera (2014) refiere que en el procedimiento penal se aglutina dos acciones: una penal y otra civil, esto por razones de economía procesal y de accesibilidad a las víctimas. Por su parte, Mir (2019) señala que "el autor del delito deberá reparar el daño económico causado o indemnizar los perjuicios mediante el pago de una cantidad”. En la práctica judicial a nivel nacional en nuestro país es común que una conducta penal también debe ser sancionada con una reparación civil. Lo que se practica en mérito a lo previsto en el artículo 92 del Código Penal: "La reparación civil se determina conjuntamente con la pena".

Se sabe que un hecho ilícito de connotación penal genera un daño o lesión concreta. Polaino-Orts (2006) refiere que "[una conducta ilícita] es la manifestación al exterior de la voluntad criminal mediante una conducta perturbadora de un bien jurídico normativamente reconocido, o el de la criminalización de los delitos de peligro abstracto". Y la responsabilidad civil se da cuando se causa un daño, ya que la conducta ilícita también genera un daño a un bien jurídico; aunque en el ámbito penal no toda conducta genera un daño concreto. A decir de Taboada (2018) el objetivo de la responsabilidad civil no es sancionar las conductas antijurídicas, sino que indemnicen los daños causados.

En tal contexto, en el Derecho Penal existen delitos de peligro abstracto donde la conducta del imputado no produce un daño concreto en el exterior, es decir, se sanciona a la persona por el solo hecho de haber desobedecido la norma penal. Al respecto Roxin (2010) sostiene "[los delitos de peligro abstracto] son aquellos en los que se castiga una conducta típicamente peligrosa como tal, sin que en el caso concreto tenga que haberse producido un resultado de puesta en peligro". Si bien por dicha conducta es legal que se sancione penalmente, siendo que está previsto en el Código Penal y por principio de legalidad se tiene que sancionar a los responsables de la comisión de delitos. Más aún que el delito debe ser sancionado en un Estado de Derecho Constitucional, por cuanto las normas deben ser de observancia obligatoria de todos los ciudadanos. Al respecto Rubio (2017) señala que la obligatoriedad de las normas constitucionales [o legales] alcanza a todos quienes ejerzan poder público, así como a las personas y a la sociedad.

Es así que surge la inquietud, en los delitos donde no existe un daño concreto -más solamente la mera vulneración de la norma penal-. ¿Es posible que pueda exigirse que se imponga una reparación civil? Es decir, al no existir un daño en el ámbito exterior tiene sentido que se imponga al imputado algún monto dinerario por concepto de reparación civil. Villanueva (2017) señala "en los delitos de peligro abstracto no es posible pronunciarse sobre la reparación civil, toda vez que no hay daño civil que reparar”. Ya que es requisito sine qua non el daño o perjuicio, ello determina el alcance de reparar; si no hay daño no hay derecho a recibir indemnización alguna (Isaza, 2011).

Empero, la Corte Suprema de nuestro país en el Acuerdo Plenario N 06-2006/CJ-116 sostiene que en los delitos de peligro abstracto debe imponerse una reparación civil, pero no explica porque debe imponerse. De esa manera, el criterio de la Corte Suprema puede ser que va en contra de lo dispuesto por la normatividad civil en temas de responsabilidad civil extracontractual, siendo que al no existir un daño lo lógico sería que no deba pagarse monto dinerario alguno. Ya que "el perjuicio o daño sufrido debe encontrarse debidamente acreditada en dos aspectos: su existencia material y su equivalente monetaria” (Isaza, 2011).

De adoptarse la postura de que debe imponerse monto dinerario por concepto de reparación civil en delitos de peligro abstracto se estaría afectando el derecho fundamental a la motivación, siendo que las decisiones judiciales deben estar motivadas. Ezquiaga (2013) señala "el derecho peruano es rotundo y reiterativo en exigir la motivación de las decisiones judiciales en todos los ámbitos”. Lo que implica que debe existir un soporte probatorio para justificar porque debe imponerse dicho monto, pero ello en la práctica judicial no se está dándose. $\mathrm{Y}$ es muy probable que no se va poder dar, por cuanto en los delitos de peligro abstracto al no existir daño concreto no existe fundamento ni es posible que exista medio probatorio que respalde la determinación de la reparación civil. 
De esa manera, los jueces del Poder Judicial al momento de imponer la reparación civil en los delitos de peligro abstracto en las resoluciones judiciales no están justificando o motivando, lo que afecta el derecho a la debida motivación.

Ya que todos los peruanos queremos que la administración de justicia sea la más justa. Una de las maneras de demostrar esa justicia es que las decisiones de nuestros jueces sean motivadas. Solo a través de los fallos motivados conoceremos cual fue la verdadera razón para llegar a dicha conclusión, porque de no haberla simplemente no se está haciendo justicia.

\section{Objetivos Específicos}

Como objetivos específicos se ha planteado los siguientes:

- Conocer la naturaleza jurídica de la reparación civil en el ámbito penal.

- Conocer los criterios que usaron los jueces para determinar la reparación civil en los delitos de peligro abstracto, de acuerdo a la jurisprudencia nacional.

- Analizar la afectación del derecho a la debida motivación en las sentencias judiciales al momento de determinarse la reparación civil en delitos de peligro abstracto.

\section{MATERIALES Y METODOS}

\section{Diseño de investigación}

El diseño de investigación fue de paradigma cualitativo. Al respecto Hernández, Fernández \& Baptista (2014) sostienen que el propósito es examinar la forma en que los individuos perciben y experimentan los fenómenos que los rodean, profundizando en sus puntos de vista, interpretaciones y significados. Por su parte Niño (2011) señala que se centra en la exploración de un limitado, pero detallado número de casos considerados interesantes y su meta es lograr profundidad. Al ser una investigación netamente documental, se basó en el análisis de textos extranjeros y nacionales, análisis de jurisprudencia nacional respecto de la problemática de la reparación civil en los delitos de peligro abstracto.

\section{Tipo de investigación}

El tipo de investigación fue jurídico-doctrinal. "Cuando se habla de investigación jurídica el termino se limita a la documental, que de preferencia se aplica al área dogmática” (Hernández \& López, 2002). En la investigación cualitativa-doctrinal nos referimos a las creaciones intelectuales del ser humano expresados en documentos escritos (Charaja, 2011). En la investigación se usó dicho tipo de investigación a fin de analizar la naturaleza jurídica de la reparación civil en los delitos de peligro abstracto, los criterios que los operadores jurídicos han aplicado para imponer la reparación civil en este tipo de delitos y finalizar con el análisis de la afectación al derecho de la motivación de resoluciones judiciales.

\section{Método}

El profesor Pineda (2017) señala que los métodos de investigación son los procesos sistemáticos que permiten ordenar la actividad de una manera formal, y la recolección de datos es el medio a través del cual el investigador se relaciona con los participantes para obtener información necesaria. En la investigación se usó el método sintético analítico, al respecto Behar (2008) señala que el análisis maneja juicios y la síntesis considera los objetos como un todo. De esa manera, este método consiste en separar el objeto de estudio en dos partes y una vez comprendida su esencia, construir un todo. Siguiendo ese método se ha estudiado cada uno de los temas materia de investigación como la reparación civil, delitos de peligro abstracto, motivación de resoluciones judiciales. Posteriormente acopiar toda la información para procesar y llegar a las conclusiones. Y apoyado con el método de la argumentación, porque se ha tenido que dar razones para tomar una determinada postura.

\section{Técnica}

Específicamente se utilizó la técnica de la observación directa que "es aquella en la cual el investigador puede recoger datos de su propia observación” (Pineda, 2008). O lo que Charaja (2011) denomina análisis 
de contenido o hermenéutico. Siendo que se ha dado revisión de la fuente bibliográfica consistente en: leyes, jurisprudencia, libros, revistas, sentencias, etc.

\section{Instrumentos}

Se usaron:

- Fichas de estudio documentario, que se usó para recabar las fuentes bibliográficas.

- Guía de investigación jurisprudencial, que se usó para recabar si la Corte Suprema Penal peruana adopto algún criterio en la determinación de la reparación civil en delitos de peligro abstracto. De igual manera, se usó dicho instrumento para analizar si los juzgados penales (sea unipersonales o colegiados) de Juliaca y Puno en las sentencias condenatorias motivaron la determinación de la reparación civil en delitos de peligro abstracto.

\section{RESULTADOS Y DISCUSIÓN}

\section{Resultados sobre la naturaleza jurídica de la reparación civil en el ámbito penal}

Respecto a la naturaleza jurídica de la reparación civil se tiene varias posturas. Algunos autores han sostenido que es de naturaleza pública, otros señalan que es de naturaleza privada, y hay quienes refieren que es de naturaleza mixta. Se abordará cada una de ellas.

1.1. Naturaleza pública de la reparación civil

Gálvez (2015) señala que el resarcimiento del daño proveniente del delito constituye una sanción jurídico penal, cumple la finalidad de la pena. Se considera a la reparación civil como una consecuencia jurídica del delito, al igual que las penas y las medidas de seguridad. Zarzosa (2001) al respecto dice que la reparación civil no solo es de interés inmediato de la parte ofendida, sino también constituye interés mediato de la defensa social, con una efectiva e inmediata reparación civil se puede proteger la seguridad jurídica.

En el sistema anglosajón, se aprecia cada vez más la aplicación de penas no privativas de libertad (llamadas sanciones intermedias), potenciándose el uso de multas o días multas, trabajo en beneficio de la comunidad entre otras sanciones semejantes (Rodríguez c.p. Roque, 2019). "Dentro de las sanciones intermedias aparece la reparación, como una sanción penal autónoma, diferente a la pena privativa de libertad” (Rodríguez c.p. Roque, 2019). "La reparación como pena operaria aunque no se hubiera causado un daño resarcible, inclusive no habría ningún problema para imponerla en caso de delitos de peligro abstracto o de tentativa sin resultado lesivo, pues la reparación ya no se sustentaría en el daño ocasionado, sino en los mismos fines de la pena” (Galvez, 2014). Es esa línea, Galvez (2014) sostiene que la reparación civil "está orientada a la satisfacción de intereses públicos o sociales más que a tomar en cuenta el interés particular de la víctima; vale decir, protege a las víctimas en potencia y no a la víctima especifica o actual”. Por ello, la acción civil nace de los mismos hechos que motivan la acción penal o pública, y para no duplicar los procedimientos es útil extender la jurisdicción de los jueces de la acción penal (Zarzosa, 2001). Con mayor precisión Mir (2019) refiere que la pena y las medidas de seguridad pueden acarrear una tercera consecuencia jurídica: la responsabilidad civil derivada de delito. Y Galvez (2014) dice que estaría vinculada al delito, tiene naturaleza penal o que se trata de una especie de tercera vía, al lado de las penas y medidas de seguridad.

Mir (2019) siguiendo al Derecho penal español señala que ciertos efectos penales como la cancelación de antecedentes delictivos sea previa satisfacción por el culpable de su responsabilidad civil. Por el cual Mir (2019) concluye que en delitos pocos graves pueden tener mayor eficacia intimidatoria la responsabilidad civil que la penal.

De esa manera, la reparación civil tiene que ver con el autor y la vigencia de la norma, dándose prioridad a la resocialización y prevención con el pago de la obligación resarcitoria (Galvez, 2014). No se habla de reparación civil, sino de "reparación penal" a la que se le atribuye funciones de pacificación al utilizar la carga simbólica del derecho penal (Galvez, 2014). Por ello Mir (2019) dice que resultaría coherente con la 
consideración de la responsabilidad como un tercer instrumento -junto a penas y medidas de seguridad-de política criminal. Lo que es una postura interesante, pero en nuestro país no es todavía acogida.

1.2. Naturaleza privada de la reparación civil

Roque (2019) refiere que la reparación civil en el ámbito penal no es en puridad ex delicto, sino -al igual que cualquier responsabilidad civil en general- ex daño, es decir no nace del delito, sino del daño ocasionado por actos ilícitos. En esa misma línea, Hirsh c.p. Galvez (2014) señala la reparación civil no puede constituir una sanción jurídico-penal porque se sustenta en un interés particular, tiene naturaleza distinta de la pena y no cumple las funciones de esta. Siguiendo con la idea, Hirsh c.p. Galvez (2014) el derecho penal se ocupa de pretensiones penales -penas y medidas-; por el contrario, las víctimas buscan una indemnización de aquello que puede sancionarse civilmente.

Así las cosas, el fundamento de la responsabilidad civil que origina la obligación de reparar es la existencia de un daño civil causado por un ilícito penal, el que no puede identificarse como ofensa penal -lesión o puesta en peligro de un bien jurídico- (Roque, 2019). Por su parte Galvez (2014) señala que la naturaleza privada de la pretensión resarcitoria está determinada por la naturaleza privada y personal, no por la forma como se ejercita ante el órgano jurisdiccional. De igual manera, San Martin (2015) señala que la acción civil tiene naturaleza civil en el sentido estricto, privado y patrimonial. Las normas que la disciplinan gozan de naturaleza civil, no penal, cualquiera que sea la ley en la que se contemplan sus disposiciones. De igual criterio es Chunga (2016), quien sostiene la pretensión civil que se ventila en el proceso penal tiene los mismos fundamentos que la responsabilidad civil y se justifica en el daño.

La reparación debe ser equivalente al daño o perjuicio ocasionado a la víctima, a diferencia de la pena que se mide en relación a la gravedad del hecho; la reparación civil es un instituto de naturaleza civil (Roque, 2019). Por su parte San Martin (2015) sostiene que el derecho procesal penal no puede "sustituir" o "transformar" lo que el imperio del derecho material es privado". Basallo c.p. Galvez (2014) explica que la obligación de reparación del daño material o moral causado supone un deber jurídico que escapa a la esfera integral del derecho penal. De hecho, se trata de una obligación de naturaleza básicamente patrimonial y con objetivos expresamente indemnizatorios.

De los párrafos precedentes se puede sostener que la reparación civil está sometido a las reglas del derecho civil y su función es eminentemente restitutoria e indemnizatoria, y el hecho que este regulado en el Código Penal se ha hecho con el fin de facilitar a la víctima el ejercicio de su acción civil en la vía procesal penal por economía y celeridad procesal.

1.3. Naturaleza mixta de la reparación civil

Mir (2019) refiere que en la mayoría de legislaciones la responsabilidad civil se encuentra regulado por leyes civiles ajenas al Código penal. En España el Código penal regula la responsabilidad civil derivada del delito y se ventila en el mismo proceso penal. Por su parte Villegas c.p. Roque (2019) señala que esta posición en realidad no ofrece aporte alguno, sino simplemente refiere que la reparación civil tiene una doble naturaleza: civil-penal: la pretensión tendría naturaleza jurídica privada, pero el ejercicio de la acción resarcitoria en sede penal es pública.

El artículo 92 del Código Penal prescribe "la reparación civil se determina juntamente con la pena".

Discusión del presente ítem

En tal contexto, la reparación civil en el ámbito penal es un aspecto discutible. Más aún al estar regulado en la parte general del Código Penal se pensó que tenía una naturaleza pública. Pero, esa posición fue en un ámbito menor por cuanto la reparación civil busca la reparación y/o la indemnización del daño causado. Así también, lo dice Roque (2019) la naturaleza pública de la reparación civil ha sido planteada por un sector minoritario.

Por su parte, nuestra jurisprudencia no ha sido clara respecto a la naturaleza jurídica de la reparación civil. Ya que el Acuerdo Plenario Nº6-2006/CJ-116, 2006, señala en los delitos de peligro abstracto cabe imponerse reparación civil; empero, en la misma no se ha fundamentado porque debe imponerse reparación 
civil en los delitos de peligro abstracto, simplemente se han basado en señalar lo siguiente: "Esta delictiva alteración o perturbación del ordenamiento jurídico se debe procurar restablecer, así como los efectos que directa o causalmente ha ocasionado su comisión (el daño como consecuencia directa y necesaria del hecho delictivo)". Quizá por ello Gálvez (2008) sostiene que en relación al resarcimiento del daño proveniente del delito, la jurisprudencia del Poder Judicial se muestra incoherente e ineficaz. No existen criterios uniformes en cuanto a los diversos elementos vinculantes de la reparación civil proveniente de delitos de peligro. Sigue, Gálvez (2008) lamentablemente el Acuerdo Plenario 06-2006/CJ-116 en lugar de esclarecer y zanjar las cosas, ha generado mayor confusión y resulta dudoso que pueda vincular a los operadores jurisdiccionales porque no tiene sustento argumental alguno.

Posteriormente, la Corte Suprema en lo Penal ha señalado que la reparación civil tiene una tendencia privada, es así que en el Acuerdo Plenario N04-2019/CIJ-116, 2019, se indica: "Los fines de la sanción penal y de la reparación del daño son diferentes. En el primer caso, persiguen primordialmente, aunque no exclusivamente, fines preventivos -evitar futuros delitos-. Por el contrario, la responsabilidad civil busca únicamente reparar el daño causado a los perjudicados. Son, pues, dos obligaciones autónomas, con presupuestos, contenidos y finalidades distintos". De igual manera, en el Acuerdo Plenario $N^{\circ}$ 05-2008/ CJ-116, 2008, se establece que la reparación civil es una institución de naturaleza jurídico-civil que descansa en el daño ocasionado, no en el delito cometido.

Da mayor claridad, la Sala Penal Permanente de la Corte Suprema en el Recurso de Casación N - 1803-2018, 2020, en el fundamento segundo señalo: "Que la responsabilidad civil en sede penal no deriva propiamente de la comisión de una infracción penal -su fundamento no es el delito, sino el daño ocasionado-".

Gálvez (2008) señala que el Tribunal Constitucional no ha sido ajeno a esta discusión, se ha pronunciado por la naturaleza pública de la reparación civil proveniente del delito; aun cuando no proporciona fundamentos teóricos que contradigan la doctrina nacional y extranjera. $\mathrm{Y}$ en otro pronunciamiento, plasmado en el Exp. $\mathrm{N}^{\circ}$ 03588-2011-PHC/TC, fundamentos seis y ocho, sostienen que la reparación civil tiene naturaleza restitutoria e indemnizatoria que pertenecería al ámbito privado. Y el citado tribunal ha indicado: "En el Código Penal señala en el artículo 95 que la reparación civil es solidaria entre los responsables del hecho punible y los terceros civilmente obligados. Por otro lado, conforme establece el artículo 93 del Código Penal, la reparación civil tiene naturaleza restitutoria e indemnizatoria, (...)”.

De lo todo expuesto en los párrafos precedentes, nuestro criterio es que la reparación civil tiene una naturaleza privada porque la reparación civil proviene de la existencia del daño y para ello debe tomarse en cuenta las reglas de la responsabilidad extracontractual del Derecho Civil.

Por su parte Chunga (2016) señala que la legislación, la doctrina y jurisprudencia reconocen el carácter privado de la pretensión civil. En similar sentido, Mir (2019) sostiene en la legislación española la responsabilidad derivada del delito es de carácter civil, se recurre constantemente a los preceptos del Derecho civil para llenar las lagunas de la regulación del Código Penal. Por su parte Peña Cabrera (2014) señala "la responsabilidad civil es de naturaleza civil, al punto que el agraviado puede renunciar a ella o reservar su incoación para un procedimiento civil”.

Así también, según nuestro punto de vista no existe un sustento jurídico sólido como para imponerse una reparación civil por la mera vulneración de la norma, y todavía imponerse montos dinerarios inmensos. De hacerlo, solo por la peligrosidad del tipo penal se estaría valorando los mismos elementos que se tomaron para imponer la pena. O en el peor de los casos se tendría que demostrar cómo esa peligrosidad acarrea un daño. Por ello, con buen criterio Zarzosa (2001) sostiene que si bien la acción civil emana de un delito, es imprescindible determinar previamente que este haya producido necesariamente daño en el derecho subjetivo o interés privado, pues todo hombre está obligado a reparar los daños que ocasiona.

Con lo cual se concuerda, siendo que la reparación civil se debe imponerse siempre que exista un daño concreto. El Acuerdo Plenario 6-2006/CJ-116, 2006, lo dice: "El fundamento de la responsabilidad civil, 
que origina la obligación de reparar, es la existencia de un daño civil causado por un ilícito penal”. Los daños cuantificables deben ser indemnizables, el daño o perjuicio debe estar traducido en términos económicos, haber tenido consecuencias en la esfera económica o espiritual y social del afectado; por el contrario, no cabe la reparación de daños no determinados (Isaza, 2011).

Con todo lo expuesto, sostenemos que la reparación civil en el ámbito penal tiene una naturaleza jurídica privada; empero, en delitos de peligro abstracto debe haber solo indemnización a la sociedad o al Estado y no reparatoria porque no existe daño concreto a quien reparar.

\section{Resultados de los criterios que usaron los jueces para determinar la reparación civil en los delitos de peligro abstracto, de acuerdo a la jurisprudencia nacional}

Para analizar los criterios jurisprudenciales sobre la reparación civil en delitos abstractos se tiene que empezar analizando el Acuerdo Plenario $\mathrm{N}^{\circ}$ 06-2006/CJ-116, que trata sobre reparación civil y el delito de peligro; empero, en ella lamentablemente no se hace mención a ningún criterio, solo se indica que es posible imponerse reparación civil en delito de peligro abstracto. Menos se explica cómo o cuales son las razones que debe usarse para imponerse reparación civil en delitos de peligro abstracto. Al respecto Roque (2019) señala: "el cuestionamiento de la citada jurisprudencia radica en que no ha establecido criterio alguno que permita sustentar la reparación civil y cuantificar y/o determinar el daño (patrimonial o extrapatrimonial) en los delitos de peligro abstracto".

De esa manera, al no existir ningún criterio en el acuerdo plenario mencionado. Corresponde recurrir a los pronunciamientos emitidos por la Corte Suprema en materia penal. La Sala Penal Permanente de la Corte Suprema en el R. N. N 1766-2004, 2004, en el fundamento segundo, ha señalado:

“...un delito de peligro abstracto, de riesgo o de pura actividad como el Tráfico Ilícito de Drogas, cuya punibilidad por los demás tiene un origen en la situación de peligro eventual que nace de las conductas típicas, la reparación civil debe fijarse en función a la cantidad y dañosidad de la droga incautada, así como a la magnitud o entidad del hecho delictivo y el número de individuos que hayan participado en la comisión, sobre la base de los principios de suficiencia y razonabilidad y proporcionalidad".

La Sala Penal Permanente de la Corte Suprema, en el Recurso de Nulidad Nº 1895-2016, 2017, en los fundamentos 3.1 y 3.2., ha señalado que la reparación civil en delitos de peligro abstracto no es posible cuantificar los daños en montos estimados. Los jueces en la citada ejecutoria suprema han señalado:

“3.3. [...] el daño a la sociedad por el tráfico de drogas es una referencia para cuantificar el monto de reparación civil evidentemente se trata de una justificación subjetiva; igualmente, afirmar un monto estimado como consecuencia de la gravedad del daño también constituye un elemento referencial, mas no determinado ni objetivo. (...), estimar los costos del proceso de persecución y procesamiento de una persona que incurre en este tipo de delitos también es otra referencia subjetiva, aun cuando es posible realizar una tarea de determinación objetiva, que en este caso no se ha hecho. (...). 3.4. Atendiendo a estas circunstancias, fijar el monto de reparación civil, conforme establecen los artículos noventa y dos y noventa y tres del Código Penal, cuando se trata de un delito de tráfico de drogas, en el cual el daño a la sociedad puede resultar inconmensurable debido a que la sola definición del perjuicio a la sociedad por sí mismo constituye un concepto indeterminado que no es viable cuantificar. En consideración a ello, en los casos de tráfico de drogas, la reparación civil se estima esencialmente teniendo en cuenta el grado de participación en el delito, la gravedad del mismo, esto es, gran tráfico o pequeños transportes, la importancia del procesado en la red de tráfico, entre otros. En consecuencia, la reparación civil dentro de esos márgenes debe ser acorde con la trascendencia del hecho, además que no resulte simbólica e imposible de ser cumplida por el sentenciado, a riesgo de no rehabilitarse o cumplir los objetivos constitucionales de la pena y, por el contrario, estigmatizar a la persona". 
En otra ejecutoria suprema, la Sala Penal de la Corte Suprema en el R.N. N 1075-2006, 2006, en el fundamento undécimo, ha señalado:

“...nuestro ordenamiento jurídico penal se rige doctrinariamente por el principio de daño causado, cuya unidad procesal -civil y penal, protege el bien jurídico en su totalidad, así como a la víctima, por lo que no debe fijarse en forma genérica, sino que es necesario individualizarla y determinarla en forma prudencial y proporcional a la entidad del daño, a la afectación del bien, las posibilidades económicas del responsable y las necesidades de la víctima”.

Así, la Sala Penal de la Corte Suprema en el R. N. N 927-2005, 2005, en el fundamento segundo ha señalado:

“...la institución de la reparación civil tiene como objeto, reparar o compensar los efectos que el delito ha tenido sobre la víctima o los perjudicados, reconociéndole en la dogmática jurídica penal que los "hechos que constituyen ilícito penal merecen la aplicación de una pena, puesto que a la vez esos hechos pueden causar un daño a alguien, decimos que son fuente de responsabilidad civil; estos son, por lo tanto, casos de responsabilidad civil derivada del ilícito penal (...), por ende, no tiene como fundamento la responsabilidad en el delito sino en el daño ocasionado a la víctima, existiendo acuerdo mayoritario en la doctrina sobre la naturaleza civil y no penal de la responsabilidad civil ex delito...”.

Discusión en el presente ítem

Los criterios para determinar la reparación civil en delitos de peligro abstracto no han sido uniformes.

Algunos jueces imponen la reparación civil en delitos de peligro abstracto por la cantidad de droga incautada. Como en el caso resuelto por la Sala Penal Permanente de fecha 21 de setiembre de 2004, donde ha señalado: "...la reparación civil debe fijarse en función a la cantidad y dañosidad de la droga incautada, así como a la magnitud o entidad del hecho delictivo y el número de individuos que hayan participado en la comisión, ...”. Y en algunos casos se ha tomado criterios como grado de participación en el delito, la gravedad del delito, importancia del procesado en la red del tráfico, como esta expresado por la Sala Penal Permanente de la Corte Suprema en el Recurso de Nulidad N 1895-2016, 2017: "en los casos de tráfico de drogas, la reparación civil se estima esencialmente teniendo en cuenta el grado de participación en el delito, la gravedad del mismo, esto es, gran tráfico o pequeños transportes, la importancia del procesado en la red de tráfico, entre otros. (...), la reparación civil dentro de esos márgenes debe ser acorde con la trascendencia del hecho, además que no resulte simbólica e imposible de ser cumplida por el sentenciado, a riesgo de no rehabilitarse o cumplir los objetivos constitucionales de la pena y, por el contrario, estigmatizar a la persona".

Gálvez (2019) siguiendo a la jurisprudencia italiana, considera los siguientes elementos: i) Gravedad del delito, que es más intensa cuando mayor es la participación del responsable en la comisión del hecho ilícito. ii) La intensidad del sufrimiento en el ánimo, debe tomarse en cuenta la duración del dolor, la edad y el sexo del lesionado. iii) La sensibilidad de la persona ofendida o víctima, teniendo en cuenta su nivel intelectual y moral. iv) Las condiciones económicas y sociales de las partes deben ser superadas porque contrastan con el sentimiento humano y con el principio de legalidad. v) El vínculo de connubio o de parentesco, y vi) el estado de convivencia.

En tal contexto, para determinar el alcance de la obligación de reparar es necesario agotar dos etapas: i) determinar cuáles fueron los daños realmente producidos; ii) determinar su valor económico en una cantidad de dinero (Isaza, 2011). En sí, el daño debe probarse con medios probatorios que demuestren los daños causados y cuanto se gastó en esos daños, lo que es coherente con lo que sostiene Isaza (2011) que debe contar con pruebas que determinen los elementos necesarios para realizar el cálculo de la indemnización; de otro lado, el causante del daño debe estar en capacidad de saber que el valor que reclaman corresponde realmente al valor de la indemnización.

La Sala Penal de Apelaciones de la Corte Superior de Justicia de Puno, en el Expediente N ${ }^{\circ}$ 00241-2011-36, seguido en contra de Gabriel Omonte Calixto, por el delito de tráfico ilícito de drogas, en agravio del Estado, al citado sentenciado se le encontró 70 kilos de pasta básica de cocaína. La mencionada Sala Penal confirma 

CIVIL EN D...

la sentencia de primera instancia, donde se impuso una reparación civil de treinta y ocho mil soles, con el fundamento:

“...considerando la naturaleza del ilícito penal investigado, se colige que la protección del bien jurídico tutelado es la salud pública, y dada la naturaleza del ilícito, no es posible efectuar una cuantificación exacta, por lo que debe imponerse el pago de la reparación civil en obediencia al principio de la prudencia, esto es, que se imponga un monto razonable a las circunstancias del ilícito. Al respecto es menester señalar que el transporte de la cantidad de droga, importa una cantidad importante de droga con efectos devastadores en la posibilidad de consumo del mismo por los jóvenes adolescentes, y el daño a la economía nacional en caso de ingresar en el circuito económico el producto de la venta de la misma, ya de dinero, ya de bienes".

Finalmente, en el Recurso de Nulidad N ${ }^{\circ} 2214-2016,2018$, a pie de página se indica: "El ponente (juez Salas Arenas) estima que el debate de la materia sobre la reparación en delitos de peligro probablemente merezca en el futuro replanteamiento jurisdiccional a escala de acuerdo plenario que modifique pronto el actual sentido establecido". Lo que evidencia que la reparación civil en delitos de peligro abstracto no está adecuadamente establecida en el Acuerdo Plenario $\mathrm{N}^{\circ}$ 06-2006/CJ-116; sino, que debe reestructurarse para una mejor administración de justicia.

En otro de los delitos donde la reparación civil es discutible, es en el delito de conducción en estado de ebriedad, donde la reparación civil se impone en mérito a una tabla de reparación civil, a cuanto más consumo de alcohol más es la reparación civil, lo que según nuestro punto de vista no es la adecuada, porque una reparación civil no puede estar parametrado a un reglamento, sino que esta tiene que tener otros indicadores, ya que aceptar la sola valoración de la tabla de reparación civil, incluso sería adoptar la teoría de prueba plena, lo que esta proscrito en nuestra nueva legislación procesal penal.

TABLA 1

Tabla de referencias para determinar la reparación civil en el delito de conducción en estado de ebriedad

\begin{tabular}{|c|c|c|c|}
\hline \multicolumn{2}{|c|}{ Periodos de Alcoholemia } & \multirow{2}{*}{$\begin{array}{l}\text { Vehículo motorizado } \\
\text { menor de } 04 \text { ruedas } \\
\text { (incluye } \\
\text { cuatrimotos) }\end{array}$} & \multirow{2}{*}{$\begin{array}{l}\text { Vehículo } \\
\text { motorizado de } 04 \\
\text { ruedas a más (no } \\
\text { incluye } \\
\text { cuatrimotos) }\end{array}$} \\
\hline $\begin{array}{l}\text { 1er Periodo de } \\
\text { Alcoholemia: } \\
\text { subclínico }\end{array}$ & $\begin{array}{l}\text { De } 0.25 \text { a } 0.5 \\
\text { g/l. (Ley N } \\
\text { 29439) }\end{array}$ & & \\
\hline $\begin{array}{l}\text { 2do Periodo de } \\
\text { Alcoholemia: } \\
\text { ebriedad }\end{array}$ & $\begin{array}{l}\text { Más de } 0.5 \text { a } 1.0 \\
\text { g/l. Más de } 1.0 \mathrm{a} \\
1.5 \mathrm{~g} / \mathrm{l} \text {. }\end{array}$ & $\begin{array}{l}5 \% \text { UIT a } 50 \% \text { UIT } 10 \% \\
\text { UIT a } 50 \% \text { UIT }\end{array}$ & $\begin{array}{l}10 \% \text { UIT a } 1 \text { UIT } \\
15 \% \text { UIT a } 1 \text { UIT }\end{array}$ \\
\hline $\begin{array}{l}\text { 3er Periodo de } \\
\text { Alcoholemia: } \\
\text { ebriedad absoluta }\end{array}$ & $\begin{array}{l}\text { Más de } 1.5 \text { a } 2.0 \\
\text { g/l. Más de } 2.0 \text { a } \\
2.5 \text { g/l. }\end{array}$ & $\begin{array}{l}15 \% \text { UIT a } 1 \text { UIT } 20 \% \\
\text { UIT a } 1 \text { UIT }\end{array}$ & $\begin{array}{l}20 \% \text { UIT a } 1.5 \text { UIT } \\
25 \% \text { UIT a } 1.5 \text { UIT }\end{array}$ \\
\hline $\begin{array}{l}\text { 4to Periodo de } \\
\text { Alcoholemia: } \\
\text { grave alteración } \\
\text { de la conciencia }\end{array}$ & $\begin{array}{l}\text { Más de } 2.5 \text { a } 3.0 \\
\text { gll. Más de } 3.0 \text { a } \\
3.5 \text { gll. }\end{array}$ & $\begin{array}{l}25 \% \text { UIT a } 1 \text { UIT } 30 \% \\
\text { UIT a } 1 \text { UIT }\end{array}$ & $\begin{array}{l}30 \% \text { UIT a } 2 \text { UIT } \\
35 \% \text { UIT a } 2 \text { UIT }\end{array}$ \\
\hline $\begin{array}{l}\text { 5to Periodo de } \\
\text { Alcoholemia: } \\
\text { coma }\end{array}$ & Más de $3.5 \mathrm{~g} / \mathrm{l}$. & 35\% UIT a 1 UIT & $40 \%$ UIT a 2 UIT \\
\hline
\end{tabular}

Nota: Resolución de la Fiscalía de la Nación N²508-2013-MP-FN

Entonces al no existir criterios uniformes. Según nuestro punto de vista los criterios que pueden tomarse para determinarse la reparación civil en delitos de peligro abstracto son los siguientes:

- Debe determinarse la clase de delito y el bien jurídico que se afectó. Se tiene que analizar si es un delito grave o leve, así como determinarse si existió afectación al bien jurídico del tipo penal. Por ejemplo, en el 
delito de Tráfico Ilícito de Drogas (TID) la reparación civil debe ser más, que en un delito de conducción en estado de ebriedad, ya que no son delitos iguales.

- Gravedad de los hechos. Se tiene que analizar los hechos concretos, puede ser que los hechos tengan una connotación de gravedad, medianamente grave o poco grave. No es lo mismo cometer un delito de conducción en estado de ebriedad en el día, que a la una de la madrugada; tampoco es lo mismo cometer un delito de TID en organización criminal que trasladar un kilo de pasta básica de cocaína.

- Grado de participación del imputado en los hechos. En este punto se tiene que analizar si el imputado participo como autor, coautor, participe (primario o secundaria). No es lo mismo participar en calidad de autor o coautor que en calidad de cómplice.

- Si hubo proximidad de causarse algún resultado concreto. Se tiene que tomar en cuenta si hubo un acercamiento a un peligro concreto, por ejemplo, si se trata de un delito de conducción en estado de ebriedad se tiene que tomar en cuenta si esta se produjo en una zona de tráfico vehicular o en un horario escolar, etc., donde la reparación debe ser más elevada. En caso de TID, si se produjo en un establecimiento educativo o donde existen personas vulnerables, la reparación civil siempre será mayor.

- La reiterada comisión de delitos similares por parte del imputado. Aquí debe tomarse en cuenta la reiterada comisión del mismo o similar delito de peligro abstracto.

- Determinarse un monto dinerario en forma prudencial y proporcional al daño. Es decir, toda determinación de la reparación civil debe dictarse no excediéndose en el daño causado por el imputado.

\section{Resultado respecto a la afectación del derecho a la debida motivación al momento de determinarse la reparación civil en delitos de peligro abstracto}

En este punto se analizó una serie de sentencias que han emitido los jueces de primera instancia en la Provincia de San Román y Puno, con la finalidad de conocer cuáles fueron los argumentos para fundamentar la reparación civil en los delitos de peligro abstracto con la finalidad de averiguar si los jueces realmente justificaron sus decisiones al momento de determinar la reparación civil, y si dichas justificaciones superan las exigencias de la debida motivación. 
TABLA 2

Sentencias que fueron revisadas

\begin{tabular}{|c|c|c|c|}
\hline $\mathrm{N}^{\circ}$ & Expediente & Delito & $\begin{array}{l}\text { Monto de la } \\
\text { reparación civil }\end{array}$ \\
\hline 1 & $\begin{array}{l}N^{\circ} \\
1547-2014-33\end{array}$ & Tráfico ilícito de drogas & $\begin{array}{l}\text { Si. } 4390.00 \\
\text { soles }\end{array}$ \\
\hline 2 & $\begin{array}{l}N^{\circ} \\
01297-2013-45\end{array}$ & $\begin{array}{l}\text { Transporte ilícito de insumos químicos } \\
\text { y productos destinados para la } \\
\text { elaboración ilícita de drogas agravada }\end{array}$ & $\begin{array}{l}\text { S1. } 10000.00 \\
\text { soles }\end{array}$ \\
\hline 3 & $\begin{array}{l}N^{\circ} \\
0845-2013-83\end{array}$ & $\begin{array}{l}\text { Promoción o Favorecimiento al tráfico } \\
\text { ilícito de drogas }\end{array}$ & $\begin{array}{l}\text { S1. } 5000.00 \\
\text { soles }\end{array}$ \\
\hline 4 & $\begin{array}{l}N^{\circ} \\
00783-2015-99\end{array}$ & $\begin{array}{l}\text { Favorecimiento al tráfico ilícito de } \\
\text { drogas }\end{array}$ & $\begin{array}{l}\text { S1. } 3000.00 \\
\text { soles }\end{array}$ \\
\hline 5 & $\begin{array}{l}N^{\circ} \\
01327-2016-93\end{array}$ & $\begin{array}{l}\text { Favorecimiento al consumo ilegal de } \\
\text { estupefacientes mediante actos de } \\
\text { tráfico }\end{array}$ & $\begin{array}{l}\text { S1. } 5000.00 \\
\text { soles }\end{array}$ \\
\hline 6 & $\begin{array}{l}N^{\circ} \\
633-2015-56\end{array}$ & $\begin{array}{l}\text { Actos de posesión de drogas para } \\
\text { tráfico ilícito }\end{array}$ & $\begin{array}{l}\text { Si. } 1000.00 \\
\text { soles }\end{array}$ \\
\hline 7 & $\begin{array}{l}N^{\circ} \\
00219-2014-73\end{array}$ & $\begin{array}{l}\text { Promoción o favorecimiento al tráfico } \\
\text { ilícito de drogas }\end{array}$ & $\begin{array}{l}\text { Si. } 3000.00 \\
\text { soles }\end{array}$ \\
\hline 8 & $\begin{array}{l}N^{\circ} \\
02387-2017-42\end{array}$ & $\begin{array}{l}\text { Fabricación, comercialización, uso o } \\
\text { porte de armas }\end{array}$ & $\begin{array}{l}\text { Si. } 5000.00 \\
\text { soles }\end{array}$ \\
\hline 9 & $\begin{array}{l}N^{\circ} \\
01143-2015-18\end{array}$ & $\begin{array}{l}\text { Favorecimiento al consumo ilegal de } \\
\text { drogas toxicas mediante actos de tráfico } \\
\text { agravado }\end{array}$ & $\begin{array}{l}\text { S1. } 15000.00 \\
\text { soles }\end{array}$ \\
\hline 10 & $\begin{array}{l}N^{\circ} \\
00346-2010-49\end{array}$ & $\begin{array}{l}\text { Conspiración al tráfico ilícito de drogas } \\
\text { y por el delito de Lavado de activos } \\
\text {-actos de ocultamiento y tenencia }\end{array}$ & $\begin{array}{l}\text { Si. } 50000.00 \\
\text { soles }\end{array}$ \\
\hline 11 & $\begin{array}{l}N^{\circ} \\
00064-2014-78\end{array}$ & $\begin{array}{l}\text { Promoción o favorecimiento al tráfico } \\
\text { ilícito de drogas }\end{array}$ & Si. 3000.00 soles \\
\hline 12 & $\begin{array}{l}N^{\circ} \\
497-2012-89\end{array}$ & $\begin{array}{l}\text { Transporte ilícito de insumos químicos } \\
\text { y productos destinados para la } \\
\text { elaboración ilícita de drogas }\end{array}$ & S/. 5000.00 soles \\
\hline 13 & $\begin{array}{l}N^{\circ} \\
00677-2015-37\end{array}$ & $\begin{array}{l}\text { Favorecimiento y facilitación al } \\
\text { consumo ilegal de drogas toxicas } \\
\text { mediante actos de tráfico agravado }\end{array}$ & $\begin{array}{l}\text { S1. } 25000.00 \\
\text { soles }\end{array}$ \\
\hline 14 & $\begin{array}{l}N^{\circ} \\
00961-2013-68\end{array}$ & $\begin{array}{l}\text { Favorecimiento al tráfico ilícito de } \\
\text { drogas mediante actos de tráfico }\end{array}$ & $\begin{array}{l}\text { Si. } 40000.00 \\
\text { soles }\end{array}$ \\
\hline 15 & $\begin{array}{l}N^{\circ} \\
0151-2012-44\end{array}$ & Tenencia ilegal de armas & Si. 400.00 soles \\
\hline 16 & $\begin{array}{l}N^{\circ} \\
773-2014-14\end{array}$ & Tráfico de influencias & $\begin{array}{l}\text { S/. } 10000.00 \\
\text { soles }\end{array}$ \\
\hline 17 & $\begin{array}{l}N^{\circ} \\
01491-2012-71\end{array}$ & Tenencia ilegal de armas & $\begin{array}{l}\text { S1. } 4000.00 \\
\text { soles }\end{array}$ \\
\hline 18 & $N^{\circ} 73-2012-22$ & $\begin{array}{l}\text { Posesión de drogas con fines de tráfico } \\
\text { ilícito y Tenencia ilegal de armas }\end{array}$ & $\begin{array}{l}\text { Si. } 15000.00 \\
\text { soles }\end{array}$ \\
\hline 19 & $\begin{array}{l}N^{\circ} \\
997-2015-25\end{array}$ & $\begin{array}{l}\text { Actos de posesión de drogas para su } \\
\text { tráfico ilícito }\end{array}$ & S/. 500.00 soles \\
\hline 20 & $\begin{array}{l}N^{\circ} \\
151-2015-72\end{array}$ & Tenencia ilegal de armas & $\begin{array}{l}\text { Si. } 1000.00 \\
\text { soles }\end{array}$ \\
\hline 21 & $\begin{array}{l}N^{\circ} \\
193-2014-59\end{array}$ & $\begin{array}{l}\text { Favorecimiento al tráfico de drogas } \\
\text { mediante actos de tráfico agravado }\end{array}$ & $\begin{array}{l}\text { Si. } 3000.00 \\
\text { soles }\end{array}$ \\
\hline
\end{tabular}

Nota: Elaboración propia

Discusión en el presente ítem

De la revisión de las sentencias se tiene muy claro que los jueces al momento de fundamentar la reparación civil en delito de peligro abstracto se basaron solamente en la mera mención de la norma, previstos en los artículos 93 y 94 del Código Penal, así como la invocación del Acuerdo Plenario No 06-2006; pero, no se tiene un análisis de cuáles fueron los medios de prueba que sustentan o respaldan la imposición de la reparación civil en esos delitos. Los jueces no han realizado una motivación en relación a la determinación de la reparación civil en los delitos abstractos. En las resoluciones antes citadas todos los jueces se han basado 
para fundamentar la reparación civil en la simple transcripción del Acuerdo Plenario $\mathrm{N}^{\circ}$ 06-2006. Y no puede llamarse motivación la simple invocación de la norma o de un acuerdo plenario; por el contrario, ello es una motivación aparente.

Y se concuerda con lo expuesto por Guillermo (2009) cuando señala que unos de los mayores problemas es la ausencia de motivación de la sentencia en el extremo de la reparación civil. Basta leer cualquier sentencia de nuestros tribunales para constatar la absoluta falta de preocupación por cumplir con esta exigencia constitucional. De la reparación civil solo se menciona el monto a pagar, los obligados a hacerla y los beneficios con la misma, pero nadie sabe cómo se determinó la cantidad a pagar, y que clases de daños han sido comprendidos en la misma, menos todavía se hace referencia a los presupuestos de la responsabilidad civil.

Lo ideal sería que una argumentación valida debe tener sustento en medios probatorios y criterios lógicos que sustenten el por qué debe imponerse determinada suma de dinero por concepto de reparación civil en delitos de peligro abstracto. Castillo (2013) dice que motivar es un acto estatal, es un resultado del debido proceso y una decisión racional, basada en hechos, medios de prueba y aplicación del derecho. Por su parte Ezquiaga (2013) refiere que el derecho peruano es rotundo y hasta reiterativo a la hora de exigir la motivación de las decisiones judiciales en todos los ámbitos. Por su parte Figueroa (2016) señala que un buen argumento en buena cuenta resiste las diversas objeciones que se puedan plantear contra el mismo, y como tal sale indemne de los exámenes de rigor a los que pueda ser sometido.

En tal contexto, la reparación civil como se ha visto en la práctica jurídica es para imponer un monto dinerario al causante del delito, con la finalidad de que este repare el daño causado por la conducta ilícita. Para determinar el quantum debe tomarse en cuenta las reglas de la responsabilidad extracontractual: existencia del daño, factor de atribución, antijuricidad y nexo causal. Si bien a lo largo de la investigación penal, los elementos como: antijuricidad, relación de causalidad, factor de atribución son demostrados. El tema de discusión en el ámbito penal siempre fue el daño, y sobre todo como se cuantifica ese daño. Según nuestro criterio debe recurrirse a los criterios de la responsabilidad civil regulados en el Código Civil; y la que por cierto debe sustentarse con medios probatorios en relación a la cuantificación del monto de la reparación civil. Por ello Espinoza (2002) sostiene que se debe contar con instrumentos auxiliares que permitan cuantificar la magnitud de las consecuencias de un hecho dañoso, a fin de tutelar al agente dañado. En esa misma línea, Roque (2019) considera que deben estar respaldados mínimamente por ciertos elementos de convicción o medios probatorios que hagan inferir una efectiva causación de un daño civil; de no tenerse elementos de convicción o medios de prueba lo resuelto simplemente deviene en arbitrario.

Del cual se desprende que para imponer reparación civil se debe tomarse en cuenta medios probatorios que sustentan la imposición de la reparación civil. No es correcto que se imponga por la sola vulneración de la norma o por la simple protección de la norma penal, lo que no tiene sentido. Por cuanto el bien jurídico que protege un delito es distinto al daño causado por la comisión de un ilícito penal. Por ejemplo, en el delito de tráfico ilícito de drogas se protege el bien jurídico salud pública, el cual es de un interés de naturaleza global o colectiva, y este delito es de peligro abstracto; y el daño es diferente, porque en este último se tiene que analizar que se dañó y en cuanto se cuantificaría ese daño.

Así mismo, cabe señalar que los jueces al no realizar una adecuada motivación han vulnerado el derecho a la debida motivación, por cuanto la simple invocación de las normas penales y civiles y del acuerdo plenario antes citado no es una motivación suficiente, por el contrario, se cae en una motivación aparente, ya que se ha observado en las sentencias analizadas que no existen las razones por la cuales se impone la reparación civil en los delitos de peligro abstracto. Más aún que al momento de imponerse la reparación civil se impone sumas que no concuerdan con el daño realizado. Ha sido claro el Tribunal Constitucional en el Exp. $\mathrm{N}^{\circ}$ 06712-2005-PHC/TC, 2005, al señalar que: "La debida motivación debe estar presente en toda resolución que se emita en un proceso. Este derecho implica que cualquier decisión cuente con un razonamiento que no sea aparente o defectuoso, sino que se exponga de manera clara, lógica y jurídica los fundamentos de hecho y de derecho que la justifiquen”. De igual manera, el Tribunal Constitucional en el Exp. $\mathrm{N}^{\circ}$ 
02771-2019-PHC/TC, 2020, en el fundamento 3, señala: "La necesidad de que las resoluciones judiciales sean motivadas es un principio que informa el ejercicio de la función jurisdiccional y, al mismo tiempo, es un derecho constitucional de los justiciables. Ella garantiza que la administración de justicia se lleve a cabo de conformidad con la Constitución y las leyes; y que los justiciables puedan ejercer de manera efectiva su derecho de defensa".

Siendo así, el problema se deriva de la automatización de la reparación civil en los delitos de peligro abstracto, en particular en los delitos de conducción en estado de ebriedad, existe una tabla de referencias del Ministerio Público para la reparación civil, conlleva a la necesidad de aceptar el pago de determinada cantidad de dinero, según el nivel del alcohol del imputado. A más alcohol, más reparación civil (Chunga, 2016). Empero si se tiene que probar el daño, pareciera que los jueces se olvidaron que las pretensiones incluso las civiles- corresponden ser acreditadas (Chunga, 2016).

Por su parte los jueces supremos del ámbito civil de la Corte Suprema peruana han mencionado que los jueces del ámbito penal no motivan la reparación civil como debe ser. Al respecto la Sala Civil Permanente de la Corte Suprema de Justicia, en la Casación N 928-2016, 2016, señala que cabe exigir reparación civil en la vía civil, a pesar de que en la vía penal se ha fijado una reparación civil. En la citada casación en el fundamento 4.5, se señala: "La sentencia penal es deficiente para analizar los daños patrimoniales y extra-patrimoniales causados a los agraviados, así como respecto a la cantidad por los conceptos ahora demandados".

\section{CONCLUSIONES}

Primera. - La naturaleza jurídica de la reparación civil es de tendencia privada, aunque en algunos delitos de bagatela como conducción en estado de ebriedad es de tendencia pública, ya que se da preferencia al pago de la reparación civil para archivar o sobreseer un caso penal.

Segunda. - No existe un criterio uniforme sobre cómo debe determinarse la reparación civil en los delitos de peligro abstracto, ya que el Acuerdo Plenario No 06-2006/CJ-1 16 no preciso ningún lineamiento. Ante esa ausencia, los criterios a tomarse según nuestro punto de vista pueden ser los siguientes: a) Debe determinarse la clase de delito y el bien jurídico que se afectó, b) Gravedad de los hechos, c) Grado de participación del imputado en los hechos, d) Si hubo proximidad de causarse algún resultado concreto, e) La reiterada comisión de delitos similares por parte del imputado; $y, f)$ Determinarse un monto dinerario en forma prudencial y proporcional al daño.

Tercera. - Los jueces de las provincias de Puno y San Román al momento de emitir sus resoluciones judiciales no han motivado la determinación de la reparación civil, solo se han basado en la reproducción del Acuerdo Plenario No 06-2006 y de los artículos 93 y 94 del Código Penal. Realizada la revisión de las mismas, no existe una explicación de las razones de porque se impuso determinado monto dinerario, menos esas decisiones están apoyadas en medios probatorios que respalden porque se impuso determinado monto por concepto de reparación civil en delitos de peligro abstracto. Lo que demuestra que existe una afectación al derecho a la debida motivación en su forma de motivación aparente.

\section{REFERENCIAS BIBLIOGRÁFICAS}

Behar, D. (2008). Introducción a la Metodología de la Investigación. Editorial Shalom.

Castillo, J. L. (2013). La motivación de la valoración de la prueba en materia penal. GRIJLEY.

Charaja, F. (2011). El MAPIC en la Metodología de Investigación. Sagitario Impresiones.

Chunga, L. (2016, March 16). Reparación civil y delitos de peligro (I). El Peruano. https://elperuano.pe/noticia-rep aracion-civil-y-delitos-peligro-i-39168.aspx

Espinoza, J. (2002). Derecho de la Responsabilidad Civil. Gaceta Jurídica. 
Ezquiaga, F. J. (2013). Argumentación e Interpretación. Grijley.

Figueroa, E. (2016). Conozca la forma de construir una tesis de argumentación. Jurídica, 584, 3.

Galvez, T. A. (2014). El Ministerio Público y la reparación civil. Anuario de Derecho Penal 2011-2012, 179-215.

Gálvez, T. A. (2015). Nuevo orden jurídico y jurisprudencia. Ideas Solución Editorial.

Gálvez, Tomas Aladino. (2019). Decomiso, extinción de dominio, nulidad de actos jurídicos fraudulentos y reparación civil. Ideas Solución Editorial.

Gálvez, Tomás Aladino. (2008). Responsabilidad civil extracontractual y delito [Universidad Nacional Mayor de San Marcos]. http://cybertesis.unmsm.edu.pe/bitstream/handle/cybertesis/1483/Galvez_vt.pdf;jsessionid=BC1E 463C5866A7AD9B9E4B36BECBF582? sequence $=1$

Guillermo, L. G. (2009). Aspectos fundamentales del resarcimiento económico del daño causado por el delito. Revista Electrónica Del Instituto Latinoamericano de Estudios En Ciencias Penales y Criminología, 2(4), 1-23. http://www2.congreso.gob.pe/sicr/cendocbib/con4_uibd.nsf/C4D85B6E06C0144305257E7C00627 CD5/\$FILE/Ilecip_Rev_004-02.pdf

Hernández, R., Fernández, C. \& Baptista, M. (2014). Metodología de la investigación. Mc Graw Hill Education.

Hernández, S.; López, R. (2002). Técnicas de investigación jurídica. OXFORD.

Isaza, M. C. (2011). De la cuantificación del daño. Editorial TEMIS.

Mir, S. (2019). Fundamentos de Derecho penal y Teoría del delito. Editorial B de F.

Niño, V. M. (2011). Metodología de la investigación. Ediciones de la U.

Peña Cabrera, A. R. (2014). La naturaleza jurídica "civil" de la reparación en la vía criminal y su insostenible carácter accesorio en el proceso penal. Gaceta Penal \& Procesal Penal, 59, 193-204.

Pineda, J. (2008). Investigación Jurídica. Editorial "Pacifico".

Pineda, Jose. (2017). El proyecto de tesis en derecho. Editorial Altiplano.

Polaino-Orts, M. (2006). Derecho penal del enemigo. Grijley.

Roque, W. (2019). La reparación civil en delitos de Organización Criminal. Editores del Centro.

Roxin, C. (2010). Derecho Penal Parte General (Quinta Edi). Editorial Civitas.

Rubio, M. (2017). La interpretación de la Constitución segun el Tribunal Constitucional. Pontificia Universidad Católica del Perú Fondo Editorial.

San Martin, C. E. (2015). Derecho Procesal Penal Lecciones. INPECCP.

Villanueva, E. J. (2017). Análisis de la reparación civil en los delitos de peligro abstracto. Gaceta Penal \& Procesal Penal, $98,45-67$.

Zarzosa, C. (2001). La Reparación Civil del Ilícito Penal. Editorial RODHAS. 